\title{
Theoretical Investigation into Students' Study Behavior Patterns: Learning through ICT and Policy Making/Administrative Management
}

\author{
Hiroshi Hasegawa
}

\begin{abstract}
The integration of Information and Communication Technology (ICT) has enabled tertiary educational institutions to implement flexible teaching approaches in contemporary educational environments. However, prior to implementing ICT-led teaching, educators need to consider not only its possible advantages, but also their students' characteristics, behavioural patterns and attitudes towards learning. Such examination is necessary because ongoing changes in students' expectations concerning their studies should inform decision made regarding the administrative and technical management of ICT-led courses. This approach is currently disregarded by many educational institutions, especially at the tertiary level. A better understanding of students' learning environments, including their understanding of organisational tools, can influence and improve academic outcomes. Reflecting the voices of teaching staff during the process of designing new courses and course policies, this paper attempts to investigate some core dilemmas that derive from the relationship between contemporary students' study behaviour patterns and the modes of ICT learning to which they are exposed. Further, a relationship between students' study behavior patterns and policy making/administrative management is argued.
\end{abstract}

Index Terms-Student study behavioral patterns and attitudes, ICT, policy making/administrative management, flexible learning.

\section{INTRODUCTION}

Various forms of Information and Communication Technology (ICT) are employed as effective pedagogical tools in educational settings. The employment of a range of technologies can lead to great benefits for teaching staff, such as a reduced requirement to cover entire curricula during face-to-face teaching or other contact with students. This, in turn, can enable teachers to introduce extra activities or material in class. The use of tools such as Blackboard, WebCT, i-lecture and so on complements physical teaching by facilitating the necessary repetition of lesson content or activities/tasks, and ICT-supported multiple-choice online quizzes can be marked by automated marking systems. The instant availability and accessibility of information, regardless of time and location, is a particular benefit where there are large class sizes [1]. This adoption of ICT has resulted in a number of online courses offered by higher education institutions, aimed at enabling

Manuscript received October 31, 2015; revised December 20, 2015.

Hiroshi Hasegawa is with the School of Education, Curtin University, Western Australia, Australia (e-mail: h.hasegawa@curtin.edu.au). students to study with a maximum amount of flexibility. While students of higher education regularly encounter these aspects of ICT learning modes, they respond to them differently, reporting both positive and negative experiences. For example, students in one field considered several modes of instruction and expressed a preference for ICT learning modes when used for information transfer, and to enable immediate feedback from their teachers, while those in other fields preferred face-to-face learning modes for interaction with teachers and other students, acquisition of conceptual and methodical knowledge, and social support [1], [2].

As ICT becomes more common in various educational settings, discussions have tended to focus more on how technologies can be integrated into the specific pedagogy of the learning environment, rather than how technology can be used to influence the quality of students' learning outcomes. In other words, ' $\ldots$ it is not the technology itself that is valuable but the means by which it is employed' [1] p. 428. Yet many higher education institutions are unlikely to advocate further research into the effective deployment of ICT in learning environments. The current situation, in which students are given increased opportunities to access ICT in order to obtain educational information, transfer information and communicate with others in their academic learning, is indeed very attractive to many higher education institutions. However, the primary driver underpinning the promotion of this flexible pedagogical practice is the distinct financial advantage it offers to institutions in relation to reduced managerial and administrative burdens. The use of ICT to offer courses with reduced teaching staff and student contact hours between academic staff and students allows institutions to save costs by reducing academic workloads, and may even bring about a reduction in the numbers of academics an institution needs to employ.

This realisation raises the need for a discussion about current students' study expectations and behavioural patterns, as well as the administrative and technical management systems that institutions expect teaching staff to handle. While the progression of technological advancement has been gradual, and the current student is more familiar with ICT and its tools, there are, nevertheless, some procedures and organisational tools that have not been designed realistically, or have not addressed students' learning patterns adequately. Since teaching staff are responsible for conducting lessons and interacting directly with students, as well as creating lessons/course plans that comply with contemporary administrative policies regarding the engagement of ICT in educational environments, they 
are the ones best able to identify any differences between ICT application in theory and in practice, and to make fair judgements about the appropriateness or otherwise of teaching/learning styles and administrative processes.

Reflecting the voices of teaching staff during the process of designing new courses and course policies, this paper attempts to investigate some of these core dilemmas, which derive from the relationship between contemporary students study behaviour patterns and the modes of ICT learning to which they are exposed, as well as the relationship between students' study patterns and the policy making/administrative management of the courses they study. Both types of dilemma arise from the need to establish an effective flexible learning environment. The situations discussed in this paper are supported empirically by various sources including professional teaching and administrative staff at tertiary institutions in Australia.

\section{STUdENTS' StUdy BEHAVIOR PATTERNS AND ICT LEARNING MODES}

\section{A. Students with Hetero-Characteristics}

Higher education students' frequent use of and engagement with ICT for casual interactions may lead to institutions supporting the embedded belief that their students are well-equipped with sufficient ICT knowledge and Web skills to use the offered tools. Consequently, '... there is no university nowadays where students can study without some knowledge of ICT' [3] p. 5. This hypothesis, along with the attitude of current higher education management towards this entire generation of students, should not be assumed correct, and it is important to remain aware of the risk of maintaining misconceptions or overgeneralising student characteristics, rather than taking into account the broad range of students that comprise a student body, each with diverse and unique characteristics regarding their ICT usage [4].

Bennett and Maton [5] cited Bourdieu's [6] three categories for amalgamating the conceptualisation of actors in their networking field: (1) field, (2) capital, and (3) habitus. Field is the concept of social context, created by people's dominant manners of behaviour, moral standards and interests particular to given contexts. Capital is the fundamental concept of these positions such as "what underpins authority, what is valued, [and] what actors gain from their participation' [5] p. 13, and habitus is the way actors get into and learn the practices in various contexts of their daily lives. Bennett and Maton [5] p. 13, highlighted the habitus theory as applied to the current educational scene:

Different structures and practices associated with different educational contexts and different everyday contexts, enabling them [that are students] to be viewed both less homogeneously and less dichotomously. This enables a more nuanced understanding than previous conceptualizations, which have drawn a sharp distinction between the everyday world and education, without acknowledging that there are many and varied contexts in which young people engage with technology.
Hargittai [7] noted the research reported by Howards, Rainie and Jones [8] and accentuated the ICT activities with which students engage, as categorised by DiMaggio, Hargittai, Celeste and Shafer [9], as being for capitalenhancing and recreational purposes. The former category is associated with health information, banking, job searching and news, and information in this category is sought mostly by those with higher education/academic backgrounds, while the latter category includes web browsing, online gaming and gambling which tend to be engaged in by those with non-academic backgrounds. In spite of the higher-level tasks carried out by the group with higher education/academic backgrounds, it is necessary to be aware of their characteristic behaviours. For example, 'students who were 20 years old or younger reported being more engaged in instant messaging, texting, participating in social networks, downloading or streaming TV or video and uploading images than students who were aged 25 years or more' [10]. This type of computer usage is for students' pleasure rather than for capital-enhancing activities, even though it may be rationalised by their increased involvement in using ICT for organising their daily house work, social lives, professions and education [5].

These social ICT activities may not prepare students adequately for interpersonal interactions. As a result, they may feel reluctant to approach their teachers verbally, but prefer to do so via short written messages. This kind of online information interaction often includes lower-level queries, such as where and how to obtain basic information, recurrent and incessant confirmation of particular tasks, and seeking reassurance about their study progress, such as whether or not they are 'on the right track'. In this context, online students appear to be more demanding of such extensive assistance than those with face-to-face tutorial support, and this can transform to extra demands and burdens for teachers in ICT-dominated educational environments. From the teacher's perspective, students using ICT, especially those who are studying in fully online modes, are prepared to complete their studies with total independence or little extra personal assistance. As well, information transfer through verbal announcements in conventional face-to-face learning sessions requires less effort for teachers than responding to written messages. Consequently, this discrepancy in expectations between the teacher and students broadens with increasing reliance on ICT for delivering courses.

\section{B. Social Networking and Academic Purposes}

While ICT-oriented lessons and courses have been implemented in higher education under the assumption that students are highly savvy with ICT and technological devices, a careful analysis of students' characteristic behaviours is required before this assumption can be taken as accurate. This need arises from the fact that some students are not equipped to use specialised software in specific academic disciplines [1], [3], [10]. This may be interpreted as meaning that some students' general computer skills do not correspond with their familiarity with ICT for academic purposes, or that their level of ICT skill is not related to the frequency of their online activity engagement [5], [7]. On the other hand, several studies have 
shown little support for the idea that the use of ICT in education is necessarily linked to students' academic achievement [3]. There has also been little support for the concept that prior knowledge of the subject matter has more impact on academic achievement than computer confidence [1].

Students' feelings about their exposure to ICT and the universities' hypotheses regarding students' inherent technological savvy were investigated by [11], applying the Theory of Planned Behaviour to ICT use by higher education students. Their research posited that most students believed their engagement with ICT to be pleasant and expressed technological confidence, although over thirty percent of the responses indicated negative feelings and a psychological burden experienced while interacting with ICT. Their research reflected that many present-day students fail to obtain even basic subject information by accessing the specific lessons and courses provided using ICT tools, despite the fact that the use of ICT is intended to be studentfriendly or student-centred [1]. Since '... attitudes and beliefs are linked, attitudes and behaviour are linked and attitudes are essentially likes and dislikes' [11] p. 942, students may profess to be in favour of ICT for academic purposes, but not actually committed to its use for academic study.

As well as the Theory of Planned Behaviour, students' habitual academic behaviours, especially on reading tasks, can also be considered as a factor contributing to their engagement with ICT in their studies. Current university students generally tend not to read or ingest whole journal articles or books, even when required to do so [3], [5], [12], [13], cited in Hoeft [14]. This may be explained partly by their familiarity with easy online access to many different sources of concise information and text-based materials, which encourage them only to digest particular and pivotal information in minimum quantity. This passive receipt of text information, rather than the interactive activity of information exchange, causes students to feel overwhelmed [1] and eventually leads them to lose their motivation to read and to overlook the theories and/or logic behind arguments, rather than to invest their time and effort. Despite this, teachers or coordinators are required to organise ICT-based lessons around the institutional expectation that their students will read, understand and act independently. But this expectation does not necessarily reflect the reality that students tend to look for more information on the Internet, a process that may actually distance them from their academic learning [1]. From this perspective, at least, ICT-oriented lessons may be seen as counterproductive to the characteristics of contemporary students, unless (a) they are able to adapt well to handling large amounts of text information in a systematic manner, and (b) ICT-based delivery is not the primary source of information.

\section{Students' Study BeHAVIOR PATterns AND Policy MAKING/ADMINISTRATIVE MANAGEMENT}

\section{A. Student Enrolment Patterns}

The flexible learning modes facilitated by ICTsynchronised learning environments in higher education institutions enable students to select broader academic paths when navigating their courses, which can lead to unprecedented issues. For example, some local students enrolled in a course on a part-time basis believe they are thus considered to be online students, and hence not required to be on campus at all. Some students residing overseas take courses in Australia as external students on a part-time basis, because of the infeasibility of their attending classes regularly, but they in fact prefer to attend in person and make assessment presentations in front of the class while they are in Australia on holiday. Their expectation that they be treated as internal students only on some occasions derives from their interpretation of the concept of flexible learning. Another common issue is that ICT accessibility can deter students from physically attending classes. Some studies, mainly focused on the educational environment in the USA, have advocated that mandatory policies for students to attend classes are essential; absenteeism from classes, enhanced by the availability of university-wide online support, has an adverse effect on the quality of final marks or examination performance [15]. However, other studies have suggested that there is a lack of evidence to support this view as it is quite conditional in nature [16]-[19]). This may include factors such as individual student's degree of motivation, previous academic knowledge and experience, the level and scope covered by lessons or courses and the classroom environment including the individual student/teacher. Also, the concept that a students' academic development comes first and their class attendance comes second, does not seem to be proven or supported by many studies [16]. As yet, much of the literature has demonstrated the fact that students who attend classes in person tend to achieve higher academic outcomes than those with lower rates of attendance.

In spite of this, the current higher education culture is embedded deeply in student-centred pedagogy [4], and supports (or deliberately overlooks) students to be negligent with self-discipline or slow in developing studious attitudes. When students miss classes, they are unlikely to complete their tasks and assignments (on time), and they eventually tend to seek alternative ways to complete/submit assignments while avoiding penalties, perpetuating the view that penalising unsatisfactory study progress is against the fundamental concept of flexible learning. In order to discover easier ways to complete their unfinished assignments, there are some students who attempt to alter their enrolment/study modes in the middle of a semester, under the assumption that converting their enrolment/study mode, especially from internal to external, will automatically lower the assessment standard, which they think may make it easier for them to complete their assignments successfully or achieve higher marks. This is an obvious misconception, as the standards of a unit/course cannot be changed based on the enrolment mode. However, increasing numbers of students behave in this manner, partly as a result of the current flexible learning environment supported strongly by ICT.

Prior to enrolling, students should be made aware of the logistics of the various study modes made possible by ICT in the name of flexible learning [19]. The most common of 
these are "internal", "external", "full-time", "part-time", "fully-online", and "partly-online". Some lexical items are employed independently and others are intermingled and integrated. In addition, students require clear definition of key words such as "flexible learning", "e-learning", "blended learning", "online approach" "mobile learning", and "distance education", as well as various other terms employed personally by both academic and administrative staff. In fact, higher education institutions tend to use a range of sometimes poorly defined flexible learning modes. Students should be aware of this terminology in order to avoid misunderstanding/misinterpreting their study/enrolment conditions. The difference between internal and external modes, full-time and part-time modes, and fully-online and partly-online modes, are relatively easy to distinguish. However, these modes lead to eight possible combinations of study, namely (1) internal, full-time, fullyonline, (2) internal, full-time, partly-online, (3) internal, part-time, fully-online, (4) internal, part-time, partly-online, (5) external, full-time, fully-online, (6) external, full-time, partly-online, (7) external, part-time, fully-online, and (8) external, part-time, partly-online. Logically, students should not be admitted for a course as (1) or (3) above if they are to be considered as studying in the internal mode, or (6) or (8) if they are studying in the external mode (see Table I below). Nevertheless, due to a lack of standardised terminology and the potentially negative connotations attached to words such as "external" and "part-time", some students attempt to categorise themselves as flexible learners, even if their admissions are considered by teachers and administrators as external and part-time.

TABLE I: StUdent ENROLMENT Modes

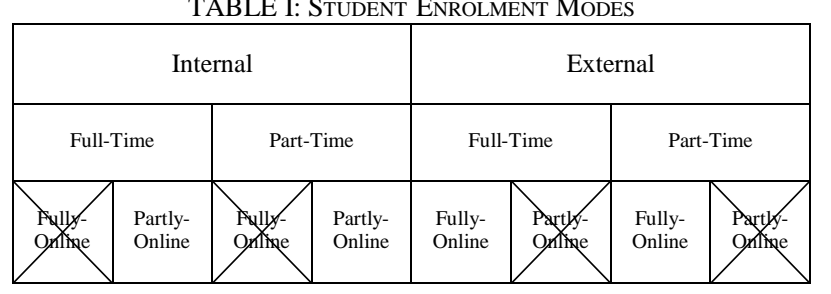

Table I above helps to accentuate the potential differences in teacher-student expectations. For example, in Pattern (5) (external full-time fully online), a teacher may tend to leave the responsibility of study to the students, presuming there is no need to contact students unless unexpected circumstances arise. It is natural for a teacher to consider that students who choose this mode will require minimal or no learning assistance. Students, on the other hand, may wish to maintain the same sense of engagement with their teachers, irrespective of their enrolment registration mode, expecting teachers to be available to clarify their study progress and solve their personal problems. The contradicting assumptions between the two parties may turn into a serious drawback, and even contribute to students deciding to discontinue their studies mid-semester.

The existence of a wide range of enrolment categories does not automatically mean that students, academic staff and administrative staff comprehend their definitions adequately or explicitly. In fact, these terms are frequently used interchangeably by connotative/denotative meanings, depending on their subconsciously cultivated understanding.
People in higher education institutions need to engage with and use ICT associated language carefully and thoughtfully, as there is a tendency to use these lexical items interchangeably, which may contribute to the expectation gap between students and teachers.

\section{B. Autonomous Learning}

The diversity of lexical items representing students' multiple methods of access to courses in which they are enrolled does indicate increased autonomy and flexibility in choosing study paths at higher education institutions. However, the flexible study opportunities offered by ICTenabled courses require self-regulated learning processes. Despite this, offering flexible learning may encourage students to believe that autonomous learning is better than face-to-face learning [2]. This may also lead to the belief that students are allowed to study in unofficial and stressfree learning environments, when in fact flexible learning modes demand that they employ a remarkable degree of autonomous learning attitudes and behaviours for success. However, ICT instructional strategies do not guarantee that students will develop the metacognitive schemes and actions expected of them by their teachers [2]. Excessive reliance on a wide array of ICT functions drastically reduces students' chances of having their study processes monitored by their teachers in class, and particularly lacking is consistency in relation to constant on-going guidance and personal encouragement for individual students. This lack of social interaction can also affect students' motivation in their studies [2], which may eventually influence their academic results. These days, many teachers note that students are reluctant to strive for high grades, and are satisfied with simply a 'pass' or avoiding a 'fail'. Higher educational institutions are not prioritising the teaching of autonomous learning skills to students, nor are they providing students with strategies for mastering the practical skills required to work successfully within the ICT-tailored learning environments. This should be worthy of careful attention and of being incorporated by higher educational institutions from now on.

The autonomous learning style of ICT-mediated learning environments may also mislead students. For example, the quantities and types of tasks assigned during self-regulated autonomous learning might differ from those assigned in traditional modes, however, the overall quality of tasks and required standard of learning should be maintained across both environments. Students should not expect educators in ICT environments to assign tasks of different quality to those assigned in regular face-to-face education, yet they do so, as if they are unable to see '... formal educational contexts and everyday contexts as being different, comprising [of] different activities with different purposes and outcomes, without necessarily privileging one over the other' [5] p. 11. Bennett and Maton [5] p. 14 insisted that 'the meaning of educational knowledge is given by its relations with other meanings rather than its social context. Moreover, these meanings are related in particular ways for the explicit purpose of formal education'. ICT environments have been established by institutions with the intention (or expectation) that students in ICT-based classes should take more responsibility for their study habits, based on careful 
consideration of individual daily and weekly routines, than students in classes with less ICT support. Despite the fact that most students are not usually self-directed or self-paced when completing tasks [1], it has become common for higher education institutions (and schools) to expect this of them, and the introduction of ICT-assisted modes to partly/primarily replace regular face-to-face interactions between teacher and students, is affecting ICT-assisted learning adversely.

Higher education students who are not ready to be responsible for their own studies, or not able to systematise their study habits effectively, are also partly a product of teaching environments in secondary schools [20], cited in Yager, Salisbury and Kirkman [21], which generally tend to spoon-feed students rather than encourage independent learning behaviours. In addition, fully-online or blended learning environments are still rare at the secondary school level. For example, even distance-education secondary school education systems targeting remote students in isolated areas in Australia require some one-to-one or faceto-face teacher-student interactions via social media and networking software. Coming from this kind of background, first-year university students tend to be unprepared for, or even unaware that, at university they are expected to have a high level of personal responsibility and self-direction [22], cited in Flynn, Concannon \& Bheachain [1]. Consequently, there are still very few secondary school graduates who are ready to study solely in the autonomous learning style encouraged in universities in Australia. It is unrealistic for universities to expect tertiary students automatically to become independent learners when they lack training in ICT cognitive literacy: that is, accessing, managing, integrating evaluating and creating information thoughtfully and effectively [23]. Since ICT-mediated education demands more and different types of student autonomy than the faceto-face mode, introducing ICT support does not automatically mean that students are sufficiently ready for the ICT-mediated learning environments [24], [25]. It is important for higher education institutions to acknowledge this and act explicitly to address it with a view to improving learning outcomes for students.

\section{CONCLUSION}

Flexible learning based on ICT enables teaching approaches that are less restricted in terms of time and location, allowing students to study independently. At the same time, ICT teaching/learning modes are designed to target students capable of independent learning. However, most students are not able to reflect this theory fully. Most students seem to comprehend the difference between regular lessons and ICT-mediated lessons as simple in-class and out-of-class learning environments. Flexible study modes are indeed appealing to many students, but it is easy for them to develop the misconception that flexible study equates to easy study, with less formality, fewer contact hours (indicating more time to study by themselves independently), reduced quality and quantity of learning content (despite this content being the same as regular faceto-face learning component), and alternative or even easier assessment tasks (although the only difference should be in how these are conducted). On one hand, students of ICToriented courses are apt to believe these misconceptions, then to enrol in courses without understanding them fully, and thus to underachieve in their studies. On the other hand, academic and administrative staff tend to operate on the assumption that students are fully aware of the conditions of online study, and differences between regular face-to-face and ICT-based delivery.

To help to solve this problem, three suggestions are made here. The first is to organise guidance/orientation sessions targeting students enrolling in courses with ICT-mediated, flexible-approaches. The pitfalls explained above are unique to ICT environments and do not occur in regular face-toface education modes, so the transition from secondary schools to higher education institutions is critical, and information clarifying these characteristics should be offered prior to students' admission into higher education. The second approach is to seek official consent from students wishing to enrol in ICT-oriented courses. Detailed course information and conditions of study admission, including coordinators' expectations and possible problems, should be attached to this consent form, so that students can be provided with an opportunity to peruse and consider their choices of learning environments. The third suggestion is that students be provided with multiple opportunities for real-time communication with the course coordinator/teaching staff. For students unable to meet in person for geographical reasons, Skype or other alternative devices can be used to achieve this. The most vital point is that ICT-based delivery should not exclude mental engagement and human interaction between teacher and students, a relationship vital to effective learning and one that may be overlooked in flexible teaching/learning approaches. The current emphasis on ICT learning modes creates less effective monitoring and guiding of students' learning and reduces their motivation to reach higher achievement levels, compared with the traditional face-toface contact that offers more opportunities for motivation, monitoring and guidance to occur. To implement one or more of the three suggestions put forward in this paper, it is important to be consistent across sections/disciplines, departments, schools, faculties and institutions. Efforts and measures need to be well organised, especially for newly enrolled first-year internal students. Not all of the problems captured in this paper would be prevented by these proposed actions, but they may at least be reduced in magnitude and might increase the readiness of students, academic and administrative staff for flexible learning and ICT-supported educational environments.

\section{REFERENCES}

[1] A. Flynn, F, Concannon, and C. Ní Bheacháin, "Undergraduate students' perceptions of technology-supported learning: The case of an accounting class," International Journal on e-Learning, vol. 4, no. 4, pp. 427-444, 2005.

[2] M. Paechter and B. Maier, "Online or face to face? Students' experiences and preferences in e-learning," Internet and Higher Education, vol. 13, pp. 292-297, 2010.

[3] K. D. Wit, D. Heerwegh, and J. C. Verhoeven. (2012). Do ICT competences support educational attainment at university? Journal of Information Technology Education: Research. [Online]. 11. pp. 1-25. Available:

http://jite.informingscience.org/documents/Vol11/JITEv11p001025DeWit1037.pdf 
[4] J. Cleary-Holdforth. (June 2007). Student non-attendance in higher education. A phenomenon of student apathy or poor pedagogy? [Online]. Available: http://level3.dit.ie/html/issue5/clearyholdforth/cleary_holdforth.pdf

[5] S. J. Bennett and K. A. Maton, "Beyond the 'digital natives' debate: Towards a more nuanced understanding of students' technology experiences," Journal of Computer Assisted Learning, vol. 26, no. 5, pp. 321-331, 2010.

[6] P. Bourdieu, The Logic of Practice, Cambridge: Polity, 1990.

[7] E. Hargittai, "Digital Na(t)ives? Variation in internet skills and uses among members of the "net generation," Social Inquiry, vol. 80, no 1. pp. 92-113, 2010.

[8] P. E. N. Howard, L. Rainie, and S. Jones, "Days and nights on the internet: The impact of a diffusing technology," American Behavioral Scientist, vol. 45, no. 3, pp. 383-404, November 2001.

[9] P. DiMaggio, E. Hargittai, C. Celeste, and S. Shafer, "Digital inequality: From unequal access to differentiated use," in Social Inequality, K. Neckerman, Ed. New York: Russell Sage Foundation, 2004 , pp. 355-400.

[10] Economic and Social Research Council. (April 2012). Not all today's students are 'tech-savvy'. [Online]. Available: http://www.sciencedaily.com/releases/2012/04/120422231828.htm

[11] L. Siragusa and K. Dixon. (2008). Planned behaviour: Student attitudes towards the use of ICT interactions in higher education. Proceedings Ascilite Melbourne. [Online]. pp. 942-953. Available: http://www.ascilite.org/conferences/melbourne08/procs/siragusa.pdf

[12] H. Shenkman, "Reading, learning and thinking seminars: A template for faculty training," Learning Abstracts, League for Innovation in Community College, vol. 5, no. 1, 2002.

[13] R. Nathan, My Freshman Year; What a Professor Learned by Becoming a Student, Ithaca: Cornell University Press, 2005.

[14] M. E. Hoeft, "Why university students do not read: What professors can do to increase compliance," International Journal for the Scholarship of Teaching and Learning, vol. 6, no. 2, 2012.

[15] A. A. C. Teixeira. (September 2013). The impact of class absenteeism on undergraduates academic performance: Evidence from an elite economics school in Portugal. [Online]. Available: http://wps.fep.up.pt/wps/wp503.pdf

[16] J. C. K. Cheung, "Class attendance and performance, which comes first?" in Proc. $20^{\text {th }}$ Annual Conf. for the Australasian Association for Engineering Education, Adelaide, Australia, 2009, pp. 974-979.
[17] D. M. Horton, S. D. Wiederman, and D. A. Saint, "Assessment outcome is weakly correlated with lecture attendance: Influence of learning style and use of alternative materials," Advances in Physiology Education, vol. 36, no. 2, pp. 108-115, June 2012.

[18] J. R. Rodgers, "Encouraging tutorial attendance at university did not increase performance," Australian Economic Papers, vol. 41, no. 3 , pp. $255-266,2002$

[19] A. Williams, E. Birch, and P. Hancock, "The impact of online lecture recordings on student performance," Australasian Journal of Educational Technology, vol. 28, no. 2, pp. 199-213, 2012.

[20] J. Willison and K. O’Regan, "2020 vision: An information literacy continuum for student's primary school to post graduation," in Proc. HERDSA Conf., Sydney, 2005, pp. 633-641.

[21] Z. Yager, F. Salisbury, and L. Kirkman, "Assessment of information literacy skills among first year students," The International Journal of the First Year in Higher Education, vol. 4, no. 1, pp. 59-71, 2013.

[22] R. G. Brockett and R. Hiemstra, Self-direction in Adult Learning: Perspectives on Theory, Research, and Practice, London and New York: Routledge, 1991.

[23] C. Chinien and F. Boutin, "Bridging the cognitive divide in ICTmediated learning," in Proc. 3rd IEEE International Conf. Advanced Learning Technologies, Athens, Greece, 2003, pp. 422-423.

[24] L. Murtagh, (2012). Enhancing preparation for higher education Practitioner Research in Higher Education. [Online]. 6(1). pp. 31-39. Available: http://insight.cumbria.ac.uk/1330/1/92-445-1-PB.pdf

[25] A. G. P. Nowlan, "Motivation and learner autonomy: Activities to encourage independent study," The Internet TESL Journal, vol. 14, no. $10,2008$.

Hiroshi Hasegawa was born on October 31, 1970, Fukuoka, Japan. He has a graduate diploma in education (language teaching) completed in 1996, from University of Technology, Sydney, and finished a master of education studies (LOTE) in 1997, a master of education (TESOL) in 1998, and a $\mathrm{PhD}$ in education in 2005, all from University of Tasmania.

Dr. Hasegawa is currently a senior lecturer in the School of Education at Curtin University in Western Australia. He coordinates and teaches undergraduate units pertaining to Japanese (as a second language) and culture, and supervises postgraduate students and students completing their teaching practicum. His research interest includes second/foreign language education, ethics and education, enhancement of education through ICT-led educational reform. 